\title{
La Organización
}

\section{Mundial de Comercio (OMC)}

(Acuerdo suscrito en

Marrakech-Marruecos el

15.4.94, y aprobado por el Perú por Resolución Legislativa No. 26407, vigente desd el 1.1.1995)
Jorge I. Arce Rodríguez

Ex Director General de Aduanas

Experto Aduanero

de la OEA y del PNUD

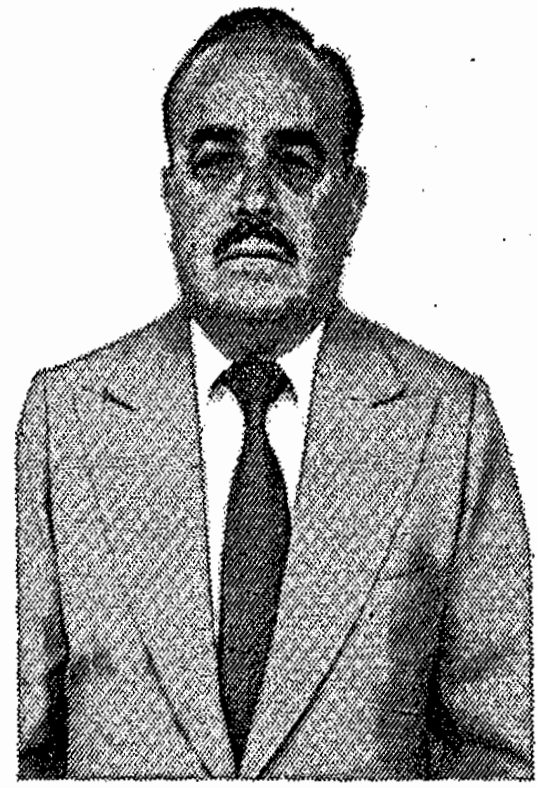

\section{ANTECEDENTES}

Cuando el mundo atravesaba un período de profunda depresión económica de los años 30, muchos países trataron de protegerse con el establecimiento de obstáculos o restricciones al comercio medianteciertas medidas, elevando aranceles, con medidas para-arancelarias, restricciones cualitativas y cuantitativas, controles cambiarios y/o tipos diferenciales, etc. etc.

En el curso de la segunda guerra mundial, se hizo evidente el riesgo de que dichas medidas restrictivas, gravitaran sobre todos los países de una manera permanente, si éstos no realizaban un esfuerzo con enérgicas medidas, para restablecer, 10 más pronto posible, el sistema de comercio multilateral que unía a las naciones del mundo, antes de dicha depresión económica.

Parahacer historia de esas tentativas hay que remontarse a la Carta del Atlántico y a los Acuer- dos de Préstamos y Arriendos, en virtud de los cuales los "Aliados", se habían comprometido a cooperar en la creación de una Organización Mundial de Comercio, fundada sobre el principio de la no discriminación, cuya finalidad principal consistiría en elevar los niveles de vida, tendiendo a favorecer el intercambio de bienes y servicios en un clima de libertad eigualdad completa.

Con esta finalidad, los Estados'Unidos de Norte América, el Reino Unido y otros países altamente industrializados, estudiaron, mucho antes de que terminara la guerra, la posibilidad de establecer organizaciones internacionales a cargo de resolver los problemas que plantearía la etapa de postguerra en materias: Monetaria, de inversiones y comerciales.

Es asi como se crearon el Fondo Monetario Internacional y el Banco Mundial de Reconstruc- ción y Fomento, en la Conferencia de Bretton Woods, antes de finalizar la guerra, pero, por diversas circunstancias, particularmente su gran alcance y la frondosidad de sus disposiciones, hasta 1948 no se terminó la Carta de la Organización Internacional de Comercio (OIC), que debería ser la tercera agencia internacional especializada en asuntos financieros.

Entre tanto los gobiernos que constituían la Comisión Preparatoria encargada por el Consejo Económico Social de las Naciones Unidas, de establecer dicha Carta, acordaron tomar como iniciativa celebrar negociaciones para la reducción de los Aranceles Aduaneros y otras medidas restrictivas al comercio sin esperar a que se creara la OIC proyectada. Esto fue un testimonio de la sinceridad de los países participantes en la preparación de la Carta dela OIC y un paso adelante para el logro de uno de sus principales objetivos. 


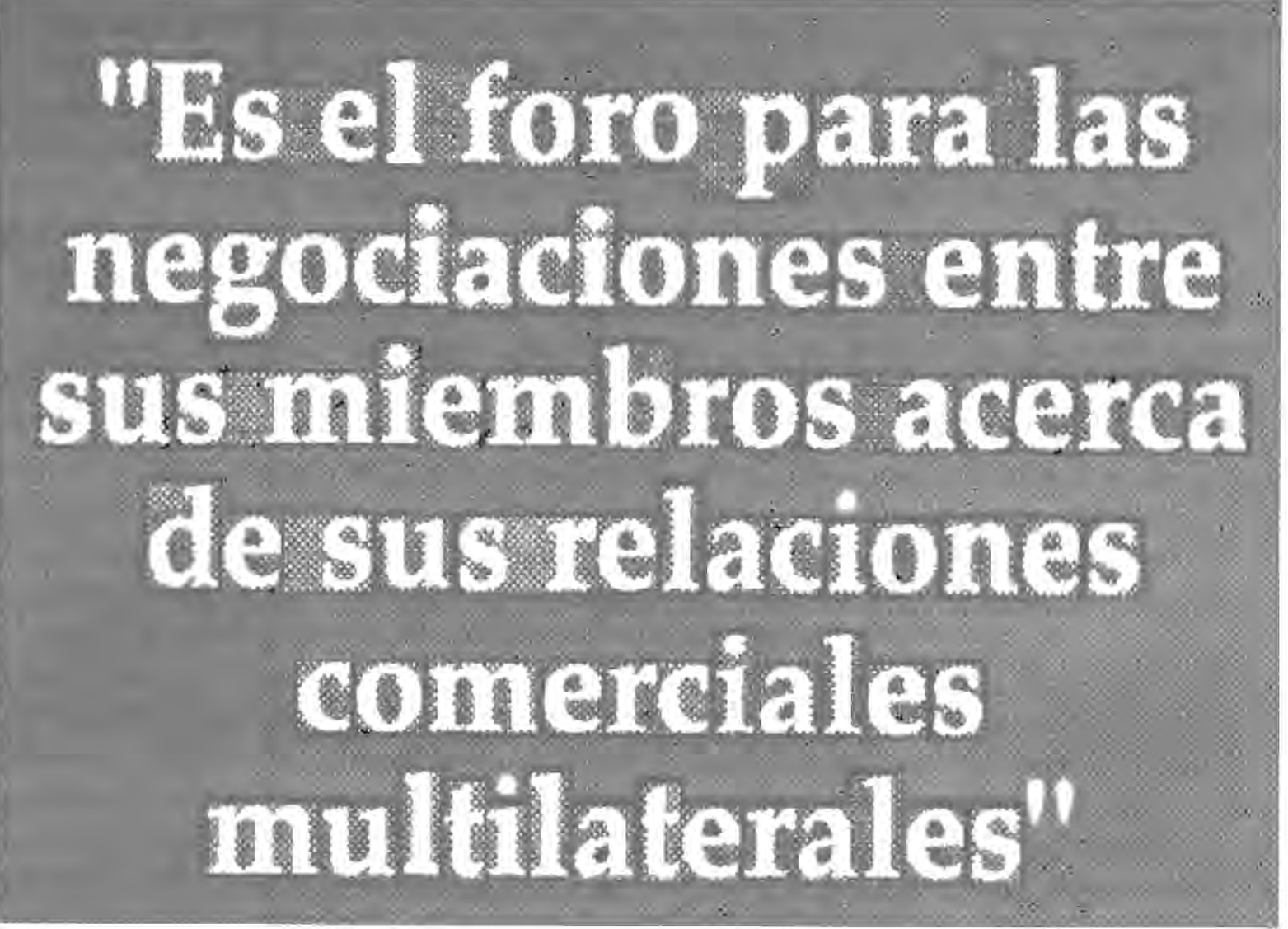

De este modo en 1947 se realizó en Ginebra, la primera Conferencia de Negociaciones Arancelarias, simultáneamente con las reuniones de la Comisión a cargo de la preparación de la Carta de la OIC.

Las Concesiones arancelarias resultantes de las negociaciones, se incluyeron en un contrato o Convenio multilateral que se designó con el nombre de:

ACUERDO GENERAL DE ARANCELES Y COMERCIO, cuya sigla en inglés se le conoce como GATT, contiene una serie de disposiciones destinadas a impedir que otras medidas proteccionistas enerven estas concesiones arancelarias, por el que cada país otorgaba mediante listas.

El GATT de 1947, firmado en Ginebra el 30 de Octubre de 1947, entró en vigor el 1.1.1948. Inicialmente lo suscribieron 23 países.

El GATT fue suscrito en un principio, como una institución provisional, en espera que entrara en vigor la Carta de la Habana en que se creara la proyectada Organización Internacional de Comercio, que habría sido un organismo internacional especializado de las Naciones Unidas, pero debido a diversas circunstancias, el GATT quedó como el único instrumento internacional que elaboraba normas de conducta comerciales aceptadas por una proporción elevada de las naciones del mundo.

\section{PARTICIPACION DEL} PERU EN EL GATT 1947

El país negocio su ingreso al GATT, en el año 1951, durante la negociación celebrada en Torquay (Inglaterra), haciendo una serie de concesiones arancelarias a las demás Partes Contratantes, mediante Lista, que el GATT, lo numeró como XXXV anexa al Acuerdo, y que se puso en vigencia mediante Oficio No. 168-S de 25.9.951, del Ministerio de Hacienda a las Aduanas.

Las NEGOCIACIONES dentro del GATT, se relizaban mediante las llamadas "Ruedas de Negociaciones", algunas de las cuales duraban 3 a 4 años y la última llevada a cabo fue la de- nominada "Rueda Uruguay" que se inició en Punta del Este, en Setiembre de 1986 y que culminó el 15 de Diciembre de 1994.

ACUERDO POR EL QUE SE ESTABLECE LA ORGANIZACION MUNDIAL DEL COMERCIO (OMC)

Art. II Ambito de la OMC: Constituyeel marco institucional común para el desarrollo de las RELACIONES COMERCIALES entre sus Miembros en los Asuntos relacionados con los Acuerdos e instrumentos jurídicos conexos incluidos en los Anexos del Acuerdo.

Los acuerdos y los instrumentos jurídicos incluídos en los Anexos 1, 2 y 3 -Acuerdos Comerciales Multilaterales-forman parte integrante de la OMC y son vinculantes para todos sus miembros.

Los acuerdos y los instrumentos jurídicos conexos incluidos en el Anexo 4 -Acuerdos Comerciales Plurilaterales-también forman parte del presente Acuerdo para los Miembros que los hayan aceptado, y son vinculantes para ellos. Estos Acuerdos Comerciales Plurilaterales no crea obligaciones niderechos para los Miembros que NO los hayan aceptado.

El Acuerdo General sobre Aranceles Aduaneros y Comercio de 1994, según se especifica en el Anexo 1A (denominado en Adelante "GATT de 1994", es jurídicamente distinto al GATT de 30 de Octubre de 1947, por estar rectificado, enmendado o modificado por el GATT 1994).

Art. III. Funciones de la OMC: Facilitar la aplicación, administración y funcionamiento de este 


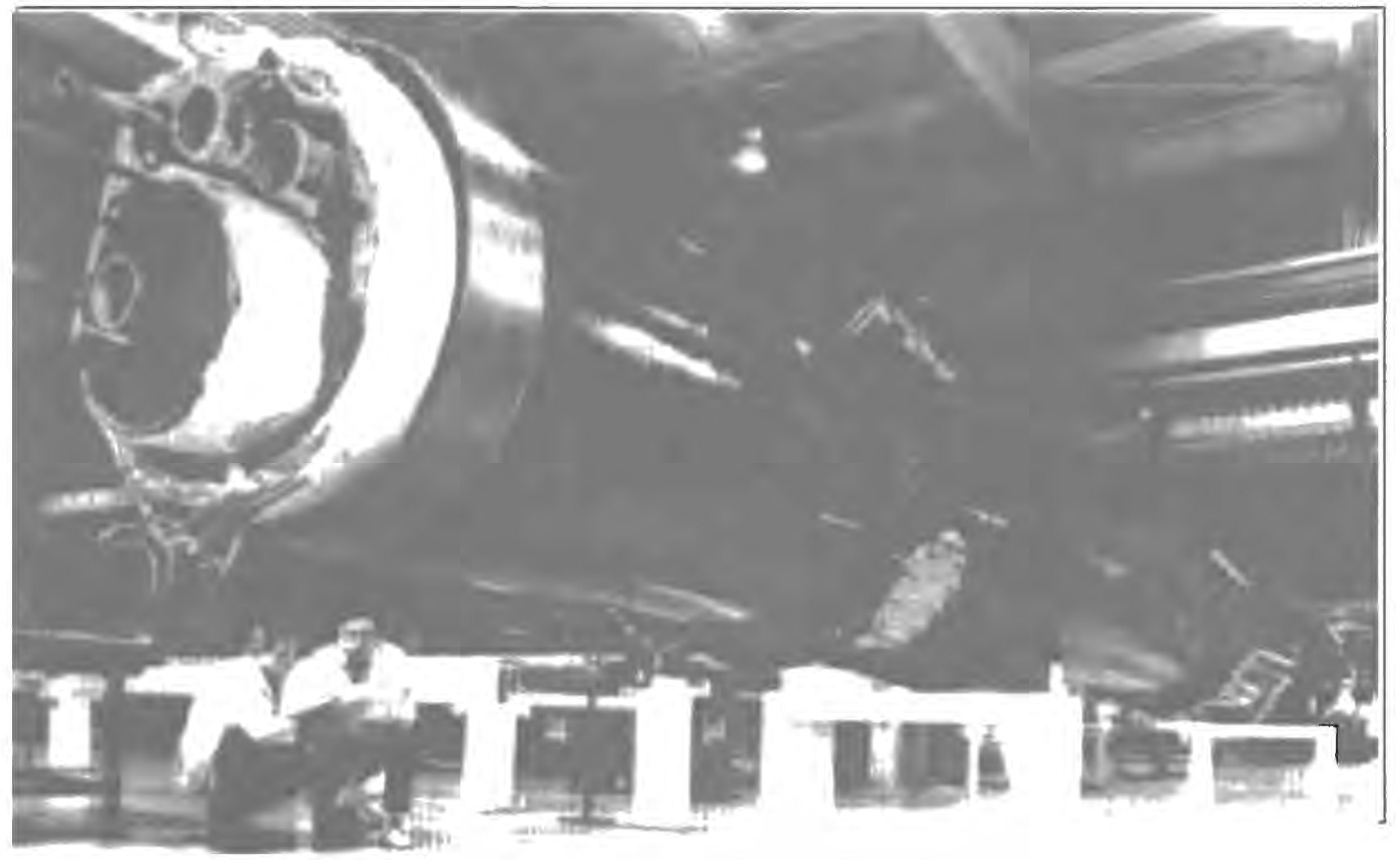

Acuerdo y de los Acuerdos Comerciales Multilaterales y favorecer la consecución de sus objetivos, constituyendo tambien el marco para la aplicación, administración y funcionamiento de los Acuerdos Comerciales Plurilaterales.

Ser el foro para las negociaciones entre sus Miembros acerca de sus relaciones comerciales multilaterales en asuntos tratados en el marco de los acuerdos uncluidos en los Anexos del presente Acuerdo y también para ultenores negociacionesentresus Miembros acerca de sus relaciones comerciales multilaterales y de marco para la aplicación de los resultados de esas negociaciones, según decisión de la Conferencia Ministerial.

Administrar el Entendimiento relativo a las normas y procedimientos, por los que se rige la solución de diferencias "Entendimiento sobreSolución de Dife- rencias" o "ESD" que figura en el Anexo 2 del Acuerdo, igualmente administrar el Mecanismo de Exámen de las Políticas Comerciales o "MEPC", establecido en el Anexo 3 del presente Acuerdo $y$; con el fin de lograr una mayor coherencia en la formulación de las políticas económicas a escala mundial, la OMC cooperará, según proceda, con el Fondo Monetario Internacional y con el Banco Internacional de Reconstrucción y Fomento y sus organismos conexos:

Art. IV. Estructura: Se establece la siguiente estructura:

1) La Conferencia Ministerial, compuesta por todos los Miembros (Se reunirá por lo menos cada dos años).

2) El Consejo General, compuesto por representantes de todos los Miembros (se reunirán según proceda para desempeñar las funciones del Organo de Solución de Diferencias; para desempeñar las funciones del Organo de Exámen de las Politicas Comerciales establecidas en el $M E P()$, las funciones de estos Or- ganos, tendrán sus propios presidentes. Se establecerán Consejos:del Comerio de Mercancias; del Comercio de Servicios; y un Consejo de los Aspectos de los Derechos de Propiedad Intelectual, relacionados con el Comercio, denominado "Consejo de los ADPIC", que funcionarán bajo la orientación general del Consejo General.

El marco de la OMC servirá de vehiculo para garantizar que los resultados de la Ronda Uruguay se traten como un "todo único" $y$, por consiguiente el hecho de ser miembro de la OMC entrañará la ACEP. TACIÓN DE TODOS LOS RESULTADOS DE LA RONDA, sin excepción alguna.

Art. V Relación con otras organizaciones: El Consejo General concertará acuerdos apropiados de cooperación efectiva con otros organismos intergubernamentales que tengan responsabilidades afines con la OMC, y podrá adoptar disposiciones apropiadas para la celebración deconsultas y la cooperación con organizaciones NOgubernamen- 
tales que se ocupen decuestiones afines a las de la OMC.

Art. VI. La Secretaría: Se crea una Secretaría de la OMC, dirigida por un Directornombrado por la Conferencia Ministerial.

Art. VIL Presupuesto y Contribuciones: Establece que el Director General, presentará al Comitéde Asuntos Presupuestarios Financieros y Administrativos, el proyecto de presupuesto y el estado financiero, el que propondrá al Consejo General un reglamento financiero en el que se establezcan, entre otros:

a) La escala de contribuciones por la que se prorrateen los gastos de la OMC entre sus Miembros;

b) Las medidas que habrá que adoptarse respecto a los Miembros con atrasos en el pago. El Reglamento Financiero se basará, en la medida en que sea factible, en las disposiciones y prácticas del GATT de 1947.

Art. VIII. Condición jurídica de la OMC: La OMC tiene personalidad jurídica y cada uno de sus Miembros le conferirá la capacidad jurídica necesaria para el ejercicio de sus funciones. Los funcionarios y los representantes de los Miembros, gozarán de los privilegios e inmunidades similares a los estipulados en la Convención de Prerrogativas e Inmunidades de los Organismos Especiales aprobados por la Asamblea General de las Naciones Unidas el 21 de Noviembre de 1947.

Art. IX. Adopción de decisiones: Todas las decisiones se adoptarán por Consenso seguida en el marco del GATT de 1947, salvolo contrario en que se entra- rá en Votación.

Art. X. Enmienda: Todo Miembro puede promover enmiendas a las decisiones del presente Acuerdo o de los Acuerdos Multilaterales del Anexo 1.

Art. XI. Miembros Iniciales: Son 125 países los que inicialmente se adhirieron al Tratado, ensu mayoria, países que conformaban el GATT y otros que estaban en vías de su adopción. Las Comunidades Europeas que aceptaron el presente Acuerdo y los Acuerdos Comerciales Multilaterales y para las cuales se anexen Listas de Concesiones y compromisos al GATT de 1994 y para las cuales se anexen Listas de Compromisos Específicos AGCS, pasaron a ser Miembros iniciales de la OMC.

Los países MENOS ADELANTADOS reconocidos como tales por las NN.UU. sólo deberán asumir compromisos y hacer concesiones en la medida compatible con las necesidades de cada uno de ellos en materia de desarrollo, finanzas y comercio o con sus capacidades administrativas e institucionales.

Art. XII. Adhesión: Todo Estado o Territorio aduanero distinto, con plena autonomía en la conducción de sus relaciones comerciales exteriores y en las demás cuestiones tratados en el presente Acuerdo podrán adherirse, esa adhesión será aplicable al presente Acuerdo y a los Acuerdos Comerciales Multilaterales anexos al mismo. La adhesión a un Acuerdo Comercial Plurilateral se regirá por las disposiciones de ese Acuerdo.

Art. XIII. No Aplicación de los Acuerdos Comerciales Multilaterales entre Miembros: El presente Acuerdo y los Acuerdos Comerciales Multilaterales enumerados en los Anexos 1 y 2 no se aplicarán entre dos Miembros, si uno u otro no consiente dicha aplicación en el Momento en que pase a ser Miembro cualquiera de ellos, etc. etc.

Art.XIV Aceptación, Entrada en vigor y depósito: Está abierta la aceptación a las Partes Contratantes del GATT 1947 y de las Comunidades Económicas Europeas y que reúnan las condiciones estipuladas en el Art. XI del presente Acuerdo para ser Miembros iniciales de la OMC.

Toda aceptación posterior a la entrada en vigor del presente Acuerdo, surtirá efecto el $30^{\circ}$ día siguiente al de la aceptación y aplicarán todas las concesiones y obligaciones establecidos en los Acuerdos Comerciales Multilaterales que hayan de aplicarse a lo largo de un plazo contado a partir de la entrada en vigor del Acuerdo, como si hubieran acpetado este instrumento en la fecha de su entrada en vigor.

Todos estos Instrumentos del Acuerdo, se depositarán en poder del Director General de las Partes Contratantes delGATT de 1947, cuando entre en vigor el presente Acuerdo, esos Acuerdos, se depositarán en poder del Director de la OMC.

Art. XV. Denuncia: Todo Miembro podrá denunciar el presente Acuerdo y a los Acuerdos Comerciales Multilaterales y surtirán efecto en un plazo de seis (6) meses, contado a partir de la fecha en que lo haya recibido el Director General de la OMC. 


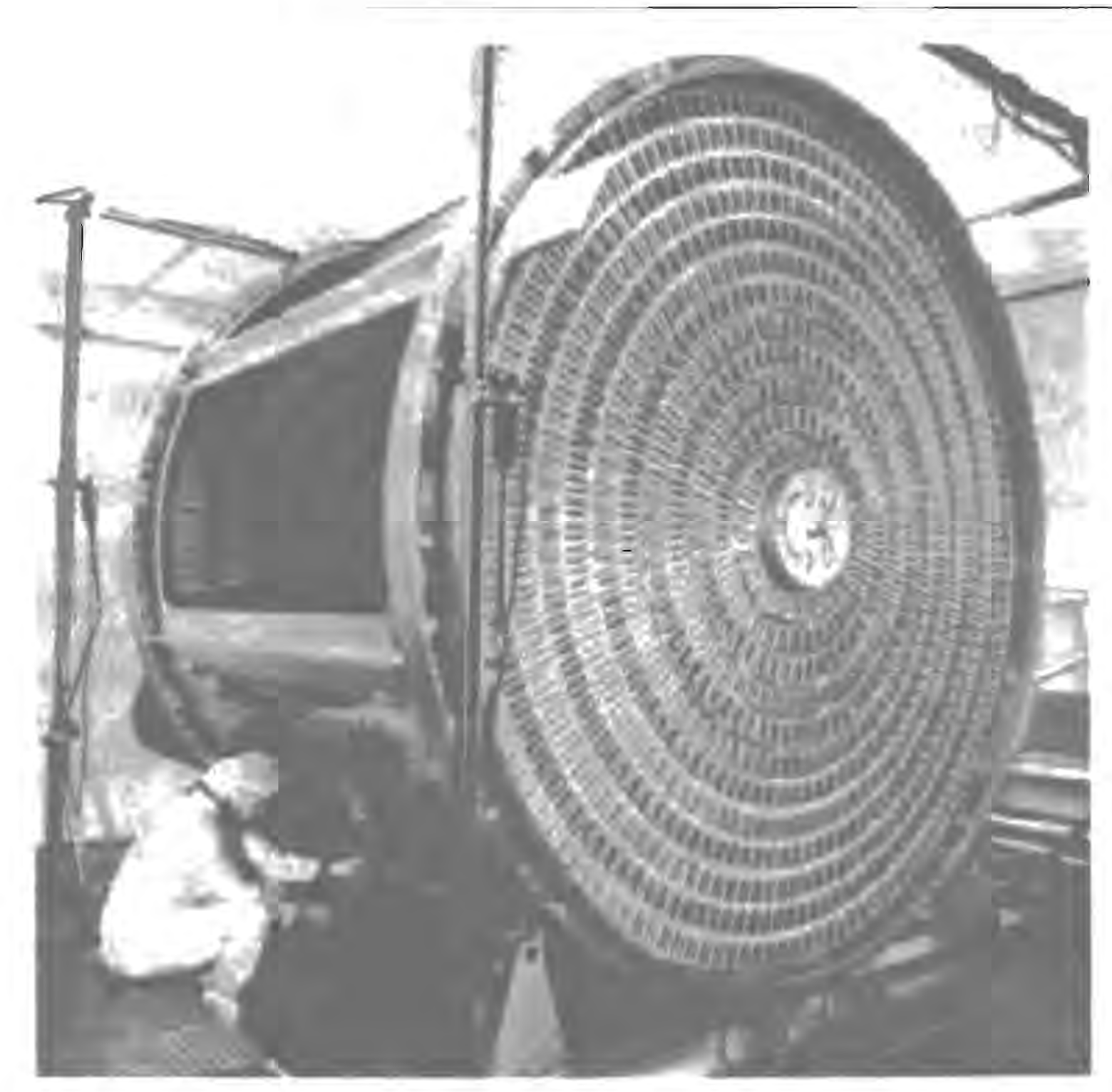

Art. XVI. Disposiciones varias: En el presente Acuerdo y en los Acuerdos Comerciales Multilaterales, la OMC se regirá por las decisiones, procedimientos y prácticas consuetudinarias de las PARTES CONTRATANTES DEL GATT de 1947 y los órganos establecidos en el marco del mismo.

Hasta que la Conferencia Ministerial nombre un Director, la Secretaría General del GATT de 1947, pasará a serSecretaría de la OMC y el Director de las Partes Contratantes del GATT de 1947 actuará como Director General de la OMC.

En caso de conflicto entre una disposición del presente Acuerdo y una disposición de cualquiera de los Acuerdos Comerciales Multilaterales, prevalecerá, en el grado en que haya conflicto, la disposición del presente
Acuerdo.

Cada Miembro se asegurará de la conformidad de sus leyes, reglamentos y procedimientos administrativos con las obligaciones que le impongan los Acuerdos anexos.

No podrán formularse Reservas respecto de ninguna disposición del presente Acuerdo. Las reservas respecto de cualquiera delas disposiciones delos Acuerdo Comerciales Multila-terales sólo podrán formularse en la medida prevista en los mismos. Las reservas respecto de una disposición de un Acuerdo Comercial Plurilateral, se regirán por las disposiciones de ese Acuerdo. El presente Acuerdo, será registrado de conformidad con las disposiciones del Art. 102 de la carta de las NN.UU.

Hecho en Marrakech, el 15 de
Abril de 1994, en un solo ejemplar y en los idiomas español, francés e inglés, siendo cada uno de los textos igualmente auténticos:

\section{1.- Notas Explicativas:}

Debe entenderse que los términos"país" y "países"utilizados en el presente Acuerdo y en los Acuerdos Comerciales Multilaterales incluyen todo territorio aduanero distinto Miembro de la OMC.

En el caso de un territorio aduanero distinto Miembro de la OMC, cuando una expresión que figure en el presente Acuerdo y en los Acuerdos Comerciales Multila-terales estécalificada por el término "nacional" se entenderá que dicha expresión se refiere a ese territorio aduanero, salvo estipulación en contrario.

ACUERDO GENERAL SO- 
BRE ARANCELES ADUANEROS Y COMERCIO DE 1994

1.- El Acuerdo General sobre Aranceles Aduaneros y Comercio de 1994 ("GATT de 1994") comprende:

a) Las disposiciones del Acuerdo General sobre Aranceles Aduaneros y Comercio, de fecha 30 de Octubre de 1947, Anexo al Acta Final adoptada al término del segundo periodo de sesiones de la Comisión Preparatoria de la Conferencia de las NN.UU. sobre Comercio y Empleo (excluido el Protocolo de aplicación Provisional), rectificadas, enmendadas o modificadas por los términos de los instrumentos juridicos que hayan entrado en vigencia con anterioridad a la fecha del Acuerdo sobre la OMC;

b) Las disposiciones de los instrumentos juridicos indicados a continuación que hayan entrado en vigor en el marco del GATT de 1947 con anterioridad a la fecha de entrada en vigor del Acuerdo sobre la OMC:

i). Protocolos y certificaciones relativos a las concesiones arancelarias;

ii). Protocolos de adhesión (excluidas las disposiciones:a) relativas a la aplicación provisional y a la cesación de la aplicación provisional; $y$ b) por las que se establece que la Parte II del GATT de 1947 se aplicará privisionalmente en toda la medida compatible con la legislación existente en la fecha del Protocolo);

iii). Decisiones sobre exenciones otorgadas al amparo del Art. XXV del GATT de 1947 aún vigentes en la fecha de entrada en vigor del Acuerdo sobre la OMC;

iv). Las demás decisiones de las PARTES CONTRATANTES del GATT de 1947,

c) Los Entendimientos indicados a continuación:

i). Entendimiento relativo a la interpretación del párrafo 1 b) del Art. II del GATT de 1994, Lista de Concesiones.

"Los países menos desarrollados sólo deberan asumit compromicos y hacer concestones en la medifla compatble con las necesidades de cada uno de ellos en materia de desamollo,
frnamas y comarcio"

ii). Entendimiento relativo a la interpretación del Art. XVII del GATT de 1994. Sobre Empresas comerciales del Estado.

iii). Entendimiento relativo a las disposiciones Arts. XII y XVII. B del GATT de 1994, en materia de balanza de pagos.

iv). Entendimiento relativo a la interpretación del Art. XXIV del GATT de 1994, sobre Uniones aduaneras y Zonas de libre Comercio.

v). Entendimiento relativo a las exenciones de obligaciones dimanantes Art. XXV del GATT de 1994;

vi). Entendimiento relativo a la interpretación del Art. XXVIII del GATT de 1994, sobre modificación de las Listas anexas al Acuerdo General (GATT), y

d) El Protocolo de Marrakech anexo al GATT de 1994.

\section{2.- Notas Explicativas.}

a) Las referencias que en las disposiciones del GATT de 1994 se hacen a una "parte contratante" se entenderán hechas a un "Miembro". Las referencias a una "parte contratante poco desarrollada" y a una "parte contratante desarrollada" se entenderán hechas a un "país en desarrollo
Miembro" y un "país desarrolladado Miembro". Las referencias al "Secretario Ejecutivo", se entenderán hechas al "Director General de la OMC".

b) Las referencias que se hacenalas PARTESCONTRATANTES actuando colectivamente en los párrafos 1, 2 y 8 del Art. XV, en el art. XXXVIII y en las notas de los artículos XII y XVIII, así como en las disposiciones sobre Acuerdos Especiales de Cambio de los párrafos 2,3,6,7 y 9 del art. XV del GATT de 1994 se entenderán hechas a la OMC. Las demás funciones que en las disposiciones del GATT de 1994 se atribuyen a las PARTES CONTRATANTES actuandocolectivamente serán asignadas por la Conferencia Ministerial;

c) i) El texto del GATT de 1994, será auténtico en español, francés e inglés.

ii) El texto del GATT de 1994 en francés será objeto de las rectificaciones terminológicas que se indican en el Anexo A del documento MTN.TNC/41.

iii) El texto del GATT de 1994 en español será el del Volumen IV de la serie de Instrumntos Básicos y Do- 


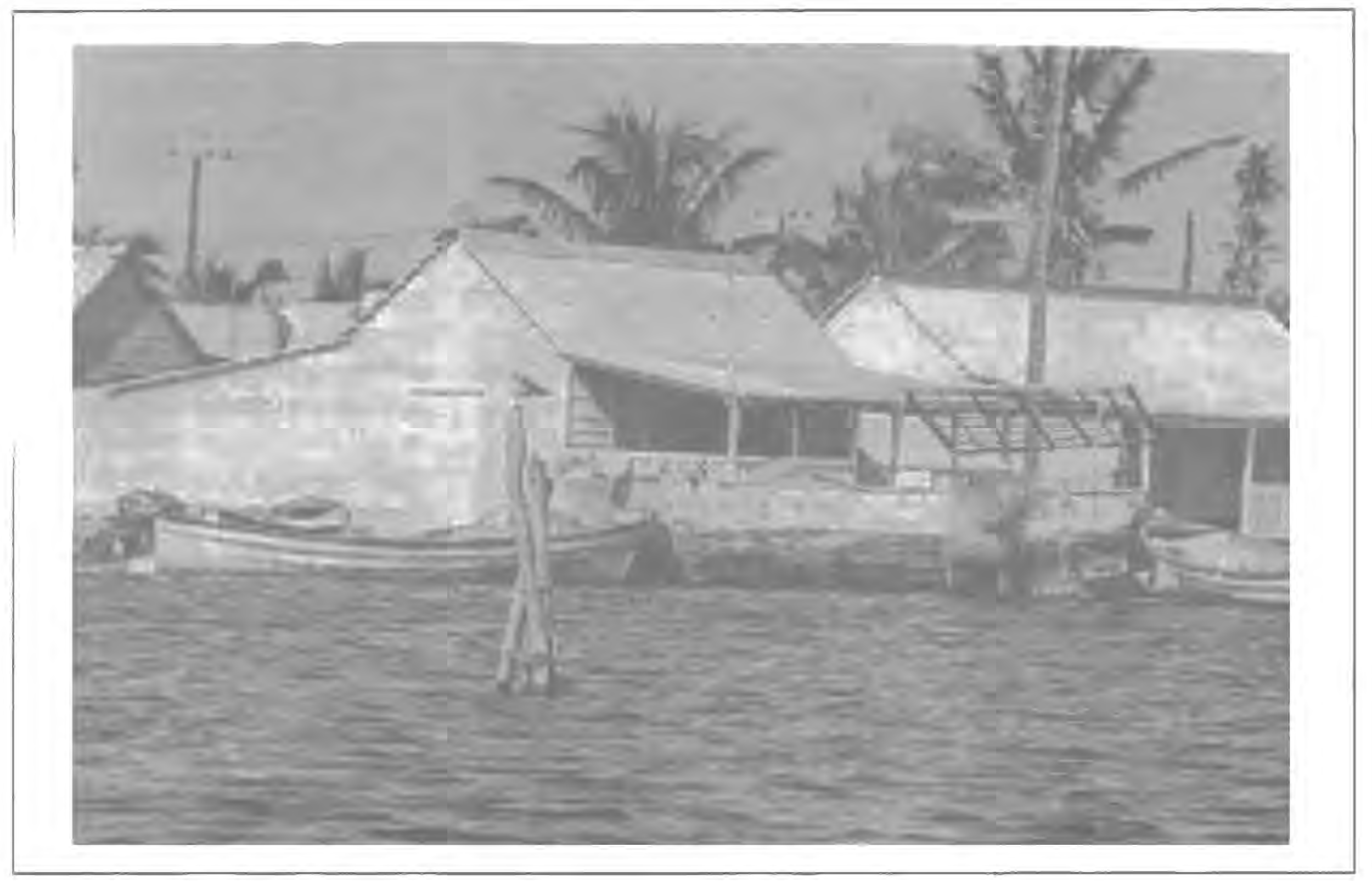

cumentos Diversos, con las rectificaciones terminológicas que se indican en el Anexo B del documento MTN.TNC/41.

3. a) Las disposiciones de la Parte II del GATT de 1994 no se aplicarán a las medidas adoptadas por un Miembro en virtud de una legislación imperativa específica promulgada por ese Miembro antes de pasar a ser parte contratante del GATT de 1947 que prohibía la utilización, venta oalquilerdeembarcacionesconstruidas o reconstruidas en el extranjero para aplicaciones comerciales entre puntos situados en aguas nacionales $o$ en las aguas de una zona económica exclusiva.

Esta exención se aplica: a) a la continuación o pronta renovación de una disposición no conforme de tal legislación; y b) a la de la disposición con la Parte II del
GATT de 1947. Esta exención queda circunscrita a las medidas adoptadas en virtud de una legislacióndel tipo descrita "supra" que se haya modificado y especificado con anterioridad a la fecha de entrada en vigor del Acuerdo sobre la OMC.Si tal legislación se modificara después de manera quedisminuyera suconformidad con la Parte II del GATT de 1994, no podrá quedar ya amparada por el presente párrafo.

b) La Conferencia Ministerial examinará esta exención a más tardar cinco (5) años después de la fecha de entrada en vigor del Acuerdo sobre la OMC y después, en tanto que la exención siga en vigor, cada dos años, con el fin de comprobar si subsisten las condiciones que crearon la necesidad de la exención.

c) Un Miembro cuyas medi- das estén amparadas por esta exención presentará anualmente una notificación estadística detallada, que comprenderá un promedio quinquenal móvil de las entregas efectivas y previstas de las embarcaciones pertinentes abarcadas por esta exención.

d) Un Miembro que considere que esta exención se aplica de manera tal que justifica una limitación recíproca y proporcionada a la utilización, venta, alquiler - reparación de embarcaciones construídas en el territorio del Miembro que se haya acogido a la exención, tendrá libertad para establecer tal limitación, previa notificación a la Conferencia Ministerial.

e) Esta exención se entiende sin perjuicio de las soluciones relativas a aspectos específicos de la legislación por ella ampara- 
da negociadas en acuerdos sectoriales o en otros foros.

\section{RESUMEN DEL ACTA FI- NAL DE LA RONDA URUGUAY}

El Acta final en que se incorporan los resultados de la Ronda Uruguay de Negociaciones Comerciales Multilaterales, es un extenso documento de más de 550 páginas en los que se plasman los resultados de las negociaciones desde que se inició la Ronda y contiene decisiones y declaraciones Ministeriales que proporcionan una mayor claridad con respecto a determinadas disposiciones de algunos acuerdos, tales como los enumerados anteriormente, $y$, engloba todas las esferas de negociaciones citadas en la Declaración de Punta del Este, con dos importantes excepciones.

LA PRIMERA, son los resultadosde las"negociaciones sobre acceso a los mercados", en las que los países han contraído compromisos vinculantes de reducción o supresión de obstáculos concretos, ARANCELARIOS Y NO ARANCELARIOS, AL COMERCIO DE MERCANCIAS, que como se menciona, estas concesiones se consignarán en "Listas Nacionales" que formarán parte integrante del Acta Final.

LA SEGUNDA, son los "compromisos iniciales" relativos a la liberalización del Comercio de Servicios. Estos compromisos también se consignarán en "Listas Nacionales".

PROTOCOLO DE LA RONDA URUGUAY ANEXO AL GATT DE 1994.

Los resultados de las negociaciones sobre los accesos a los mercados en las que los partici- pantes hayan contraído compromisos de supresión o de reducción de los tipos arancelarios y las medidas NOarancelarias aplicables al comercio de mercancías, se registrarán en las "listas naciones de concesiones" que quedarán anexas al mencionado Protocolo que a su vez forma parte integrante del Acta Final.

El Protocolo tiene cinco apéndices: Apéndice I: Sección A:Productos agropecuarios - Concesiones arancelarias en régimen de la nación más favorecida; Sección B: Productos agropecuarios Contingentesarancelarios; Apéndice II: Concesiones arancelarias en régimen de la nación más favorecida con respectoa otros productos; Apéndice III: Arancel preferencial - Parte II de las listas (de ser aplicable); A péndice IV: "Concesiones NO arancelarias Parte III de las listas; Apéndice V: Productos agropecuarios Compromisos de limitación de las subvenciones - Parte IV de las listas, Sección I: Ayuda interna: Compromisos sobre la Medida Global de Ayuda (MGA) total. Sección II: Subvenciones a la exportación: Compromisos de reducción de los desembolsos presupuestarios y las cantidades, Sección III: Compromisos de limitación del alcance de las subvenciones a la exportación.

La lista de concesiones relativas a un Miembro anexa al Protocolo pasará a ser la Lista relativa a ese Miembro anexa al GATT de 1944 en la fecha en que entre en vigor para dicho Miembro el Acuerdo por el que se establece la OMC.

Gradualidad de las reducciones arancelarias.- En lo que respecta a los productos No agropecuarios, las reducciones arancelarias acordadas por cada Miembro, se aplicarán mediante cinco (5) reducciones iguales de los tipos, salvo que se indique lo contrario en la Lista del Miembro. La primera de esas reducciones se hará efectiva en la fecha de entrada en vigordel Acuerdo por el que se establece la OMC. Cada una de las reducciones sucesivas se llevará a efecto el $1^{\circ}$ de Enero de cada uno de los años siguientes y el tipo final se hará efectivo, a más tardara los cuatro (4) años de la fecha de entrada en vigor del Acuerdo por el que se establece la OMC. No obstante los participantes podrán aplicar las reducciones en un número menor de etapas o en fechas anteriores a las indicadas.

Con relación de los productos agropecuarios, tal como se definen en el Art. 2 del Acuerdo sobre la Agricultura, el escalonamiento de las reducciones se aplicará en la forma especificada en las partes pertinentes de las listas, (Para una explicación más detallada, el Acuerdo sobre la Agricultura indica, que las medidas no arancelarias en frontera, se remplazan por aranceles, que aportan substancialmente el mismo nivel de protección. Los aranceles resultantes de este proceso de "arancelización", así como otros aranceles aplicados a los productosagropecuarios, han de reducirse en un promedio del $36 \%$ en el caso de los "países desarrollados" y del $24 \%$ en el caso de los países "en desarrollo", exigiéndose reducciones mínimas respecto de cada línea arancelaria. Reducciones que han de efectuarse a lo largo de un período de seis (6) años en el caso de los países desarrollados y de más de diez (10) años en el caso de los países en desarrollo. No se exige que los países menos adelantados reduz- 
can sus aranceles).

Decisión relativa a las medidas en favor de los países MENOS ADELANTADOS.- Una decisión relacionada con este tema establece, entre otras cosas, que no se requerirá a estos países que asuman compromisos y hagan concesiones que no sean compatibles con las necesidades de cada uno de ellos en materia de desarrollo, finanzas y comercio. Junto a otras medidas más específicas que prevén un trato flexible y favorable, también establece que podrán completar sus listas de concesiones y compromisos en las esferas de acceso a los mercados y servicios para Abril de 1995, en lugar del 15 de Diciembre de 1993. (Estos países Miembros "en desarrollo" o "menos adelantados", están clasificadosen los incisosa) y b) del Anexo VII).

\section{CONTENIDO DE LOS "EN- TENDIMIENTOS" DEL GATT DE 1994:}

Relativo a la interpretación del párrafo b) del Art. II.- Lista de Concesiones. Acuerdo de registrar en las listas nacionales los "demás derechos o cargas" percibidos además del arancel registrado y de consolidarlos a los niveles vigentes en la fecha establecida en el Protocolo de la Ronda Uruguay.

Relativo a la interpretación del Art.XVII.-Empresas Comerciales del Estado.- Acuerdo por el que se intensifica la vigilancia de sus actividades por medio de procedimientos más rigurososen materia de notificación y exámen.

Relativo a la interpretación de los Arts. XII y XVIII.B.- Disposiciones en materia de balan-

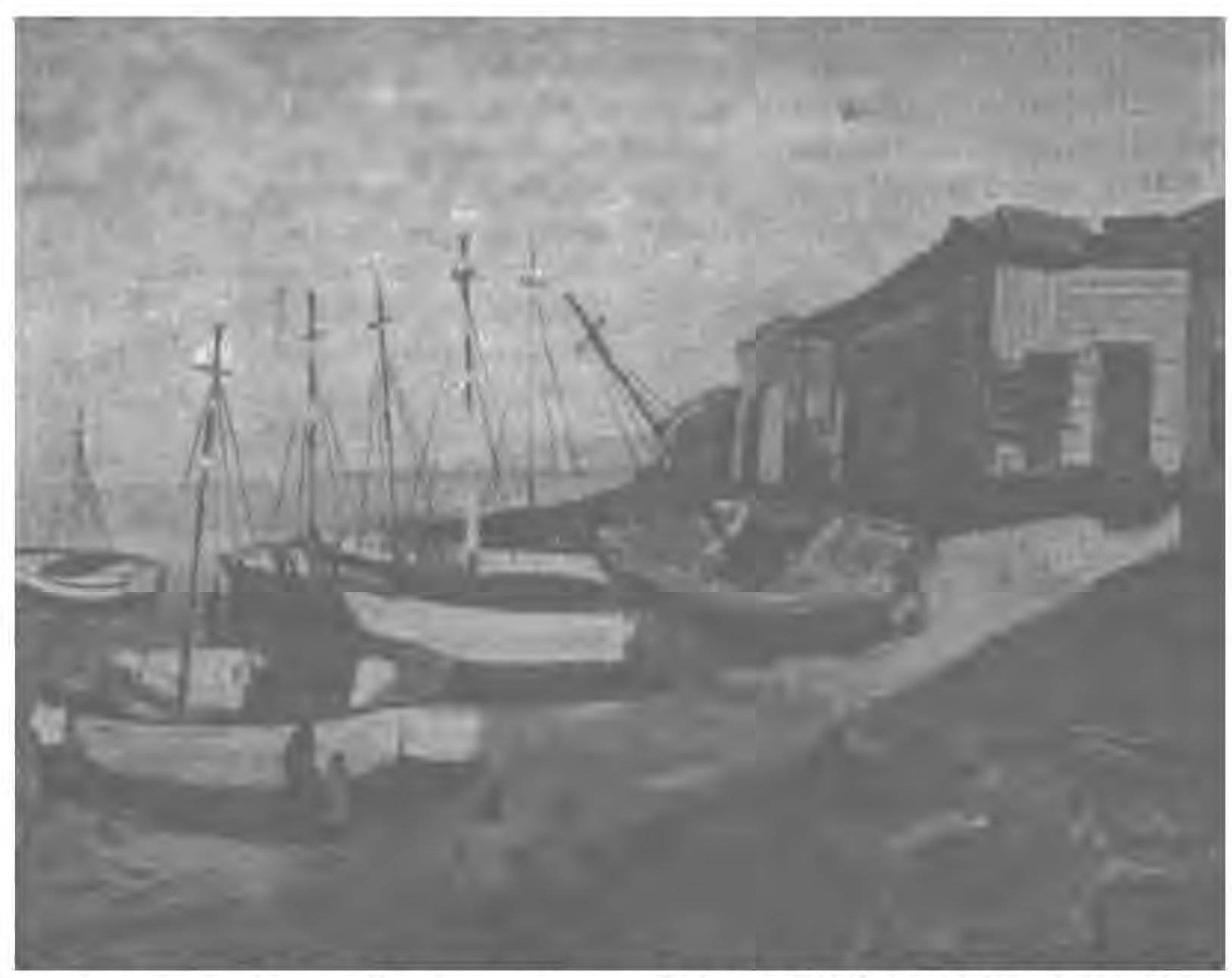

za de pagos.- Acuerdo de que las partes contratantes que impongan restricciones por motivos de balanza de pagos lo hagan de la manera que menos perturbe el comercio y utilizando preferentemente medidas basadas en los precios, como depósitos y recargos a la importación, en lugar de restricciones cuantitativas. Se convienen también procedimientos para la celebración de consultas en el Comité de Restricciones a la Importación (Balanza de Pagos) del GATT, así como procedimientos de notificación de las medidas adoptadas por motivos de balanza de pagos.

Relativo a la interpretación del Art. XXIV.- Uniones aduaneras y Zonas de libre comercio.- Acuerdo por el que se clarifican y refuerzan los criterios y procedimientos para el exámen de nuevas Uniones aduaneras o zonas de libre comercio, o ampliaciones de las existentes, y para la evaluación de sus efectos en terceras partes. Seaclara también el procedimiento que ha de seguirse para lograr la compensación que pueda ser necesaria en caso de que las partes contratantes que constituyan una Unión aduanera quieran aumentar un arancel consolidado. Se dan asimismo, aclaraciones sobre las obligaciones de las partes contratantes con respecto a las medidas adoptadas por gobiernos o autoridades regionales o locales dentro de sus respectivos territorios.

Relativo a la interpretación del Art. XXV.- Exenciones.Acuerdo sobre nuevos procedimientos para la concesión de exenciones de la disciplinas del GATT, la especificación de las fechas de terminación delas exenciones que puedan concederseen el futuro y la fijación de las fechas de expiración de las exenciones existentes. No obstante, las principales disposiciones relativas a la concesión de exenciones figuran en el Acuerdo por el que se establece la OMC.

Relativo a la interpretación del Art. XXVIII.- Modificación de las Listas anexas al Acuerdo Genera (GATT).- Acuerdo sobre nuevos procedimientos para la negociación de la compensación 
en caso de modificación o retirada de consolidaciones arancelarias, con inclusión del establecimiento de un nuevo derecho de negociación para el país para el cual las exportaciones del producto de que se trate representen la proporción más alta de sus exportaciones. Ello tiene por finalidad aumentar las posibilidades de participación en las ne gociaciones de los países de menores dimensiones y de los países en desarrollo.

Relativo a la interpretación del Art. XXXV.- NO aplicación del Acuerdo General. (Este entendimiento, está considerado como Art. XIII de la OMC).- Y es el que permite que una partecontratante o un país que acabe de adherirse al Acuerdo General (GATT), invoque las disposiciones de éste en materia de NO aplicación con respecto a la otra parte tras haber celebrado ambas partes negociaciones arancelarias. El Acuerdo por el que se establece la $\mathrm{OMC}$, prevee que cualquier invocación de las disposiciones de ese Acuerdo en materia de NO aplicación debe extenderse a todos los acuerdos multilaterales.

\section{LA ORGANIZACION} MUNDIAL DE COMERCIO, contiene además los siguientes ACUERDOS:

1.- Sobre la Agricultura

2.- Sobre Aplicación de Medidas Sanitarias y Fitosanitarias.

3.- Sobre los Textiles y el Vestido.

4.- Sobre Obstáculos Técnicos al Comercio.

5 - Sobre las Medidas en Materia de Inversiones Relacionadas con el Comercio.

6.- Relativo a la aplicación del Art. VI del GATT de 1994.

7.- Relativo a la aplicación del Art. VII del GATT de 1994, (Sobre Valoración Aduanera de las Mercancias).
8.- Sobre Inspección previa a la Expedición.

9.- Sobre Normas de Origen.

10.- Sobre Procedimientos para el trámite de Licencias de Importación.

11.- Sobre Subvenciones y medidas compensatorias.

12.- Sobre salvaguardia.

13.- Acuerdo General sobre el Comercio de Servicios.

14 - Sobre los aspectos de los Derechos de Propiedad Intelectual relacionados con el Comercio.

15.- Entendimiento relativo a las Normas y Procedimientos por los que se rige la Solución de Diferencias (Anexo 2).

16.- Mecanismos de examen de las politicas Comerciales.

EL ACCESO A LOS MERCADOS EN LA RONDA URUGUAY DE GRAN AYUDA PARA LOS EXPORTADORES DE LOS PAISES EN DESARROLLO:

Los resultados de la Ronda Uruguay, en materia de acceso a los mercados, que en la práctica se concretarán mediante la recién creada $\mathrm{OMC}$, brindan grandes oportunidades deampliación de comercio a los países en desarrollo, en lo que atañe a los productos que ya exportan y a los que ofrecen grandes posibilidades de exportación, pues, las nuevas medidas de acceso a los mercados no se refieren únicamente al comercio de productos, sino también al de servicios. (Acuerdo $\left.N^{2} 13\right)$. Entrañan además de REDUCCIONES DE ARANCELES, LA ELIMINACION progresiva del ACUERDO MULTIFIBRAS (AMF) y la incorporación de la agricultura al marco general del comercio multilateral y se han fijado asimismo, unas reglas más detallada en lo tocantea LAS MEDIDAS NO ARANCELARIAS.

\section{SINTESIS DE LOS RESUL-}

\section{TADOS}

Entre las medidas acordadas para facilitar el acceso a los mercados, y que sea más seguro, en los años venideros, cabe citar las siguientes:

1.- REDUCCION DE ARANCELES.- Los países DESARROLLADOS han aceptado, reducir sus aranceles, en el caso de productos industriales, de un promedio del $6,3 \%$ a un $3.8 \%$, esto es, una disminución del $40 \%$ por ciento.

2.- CLAUSULA DE LA NACIONMASFAVORECIDA.- La proporción de productos industriales que ENTREN EN LOS MERCADOS DE LOS PAISES DESARROLLADOS al amparo de la cláusula de la nación más favorecida (NMF), de aranceles

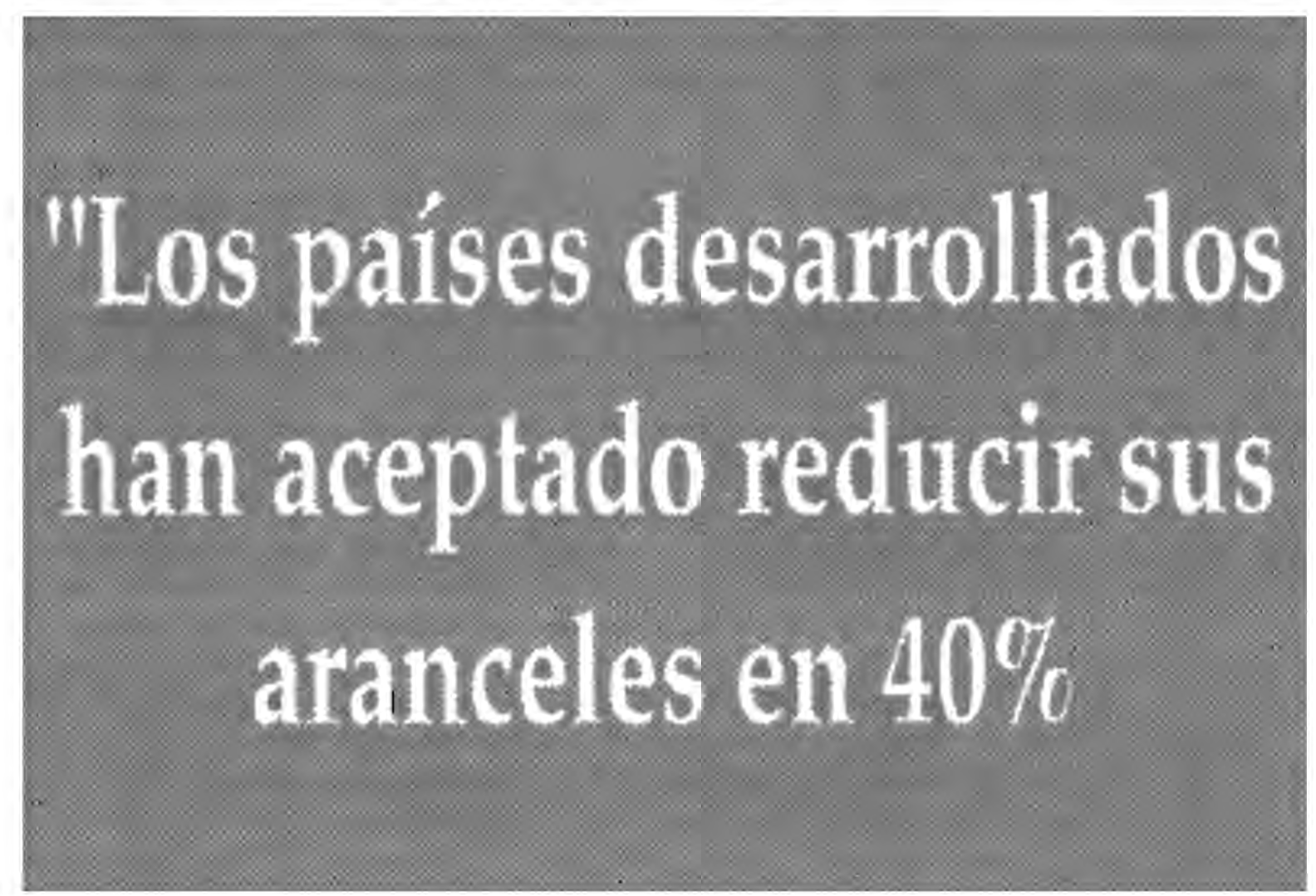


nulos, se multiplicará sobradamente por dos, al pasar de un 20 a un 44 por ciento. En el extremo superior de la estructura arancelaria, la proporción de importaciones de los países desarrollados, de todas las procedencias, sometidas a unos aranceles superiores al 15 por ciento BAJARAN de un 7 a un 5 por ciento, $y$ los procedentes de ECONOMIAS EN DESARROLLO de un 9 a un 5 por ciento.

\section{3.-ARANCELES"CONSOLI-} DADOS".-El porcentaje dearanceles consolidados para los productos industriales ha pasado de un 78 a un 99 por ciento en el caso DE LOSPAISESDESARROLLADOS, de un 21 a un 73 por ciento EN LAS ECONOMIAS EN TRANSICION, lo cual ofrece un grado mucho mayor de seguridad comercial a los negociantes y a los inversores.

NOTA.- Conviene aclarar lo que se entiende por "consolidación de aranceles" es el porcentual dado por un país para los niveles arancelarios en su negociación, y por el cual se compromete a NOSUBIR ese arancel por encima de dicho nivel (salvo mediante una negociación con los interlocutores comerciales interesados).

Pero los niveles arancelarios no son los únicos compromisos consolidables, pues, en lo tocante a los productos agrícolas, los compromisos no se refieren únicamente a una consolidación de los derechos aplicados a los productos importados, sino también a los ya citados que se refieren a las OPORTUNIDADES DE ACCESO A LOS MERCADOS, actuales y mínimas, al VALOR DE LAS SUBVENCIONES A LA EXPORTACION y al volúmen exportado con la AYUDA DE SUBVENCIONES, así como a la AYUDA INTERNA A LOS PRODUCTOS AGRICOLAS.

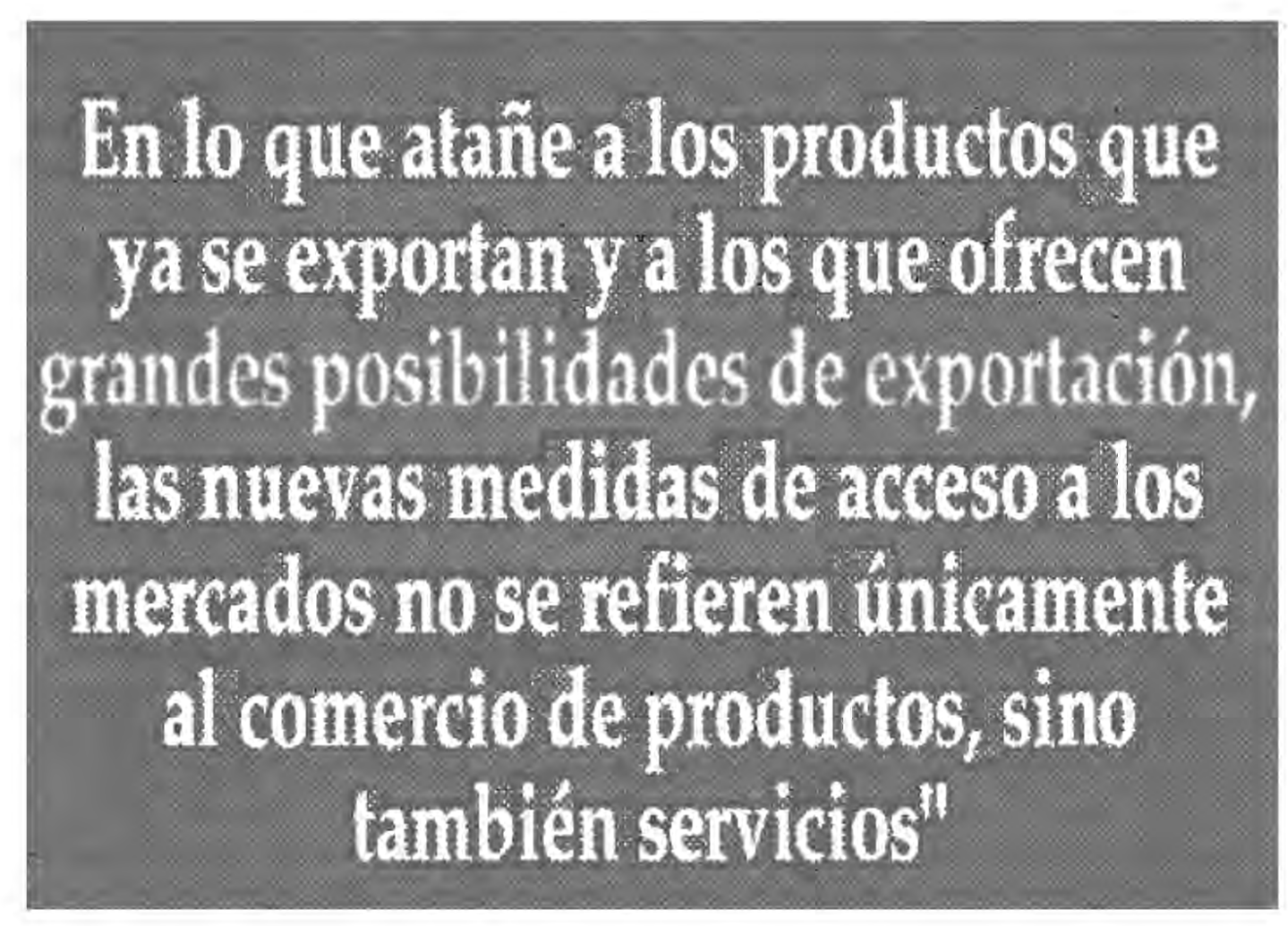

Antes de la Ronda Uruguay, solamente era "consolidable" un tercio de los aranceles de los productos agrícolas. Aunque el mayor grado de consolidación es particularmente grande en las ECONOMIAS EN DESARROLLO (de un $17 \%$ a casi un $100 \%$ delos aranceles), ha doblado casi, en las economías DESARROLLADAS Y EN TRANSICION.

En el caso de los productos industriales esa "consolidación", suele revestir la forma de unos índices máximos o topes para los aranceles aplicados a los productos enumerados en la Lista de aduanas.

\section{4.- PRODUCTOS AGRICO-} LAS.- Los compromisos de acceso a los mercados mínimo de los productos agrícolas sometidos a la " arancelización" promoverán oportunidades para grupos de productos que tienen POSIBILIDADESDE EXPORTAR los PAISES EN DESARROLLO.

Si bien el nivel global de protección de los productos agrícolas en la mayoría de los PAISES DESARROLLADOS seguirá estando muy por encima del nivel de los productos industriales con la finalización de la Ronda Uruguay, el comercio agrícola ha emprendido la senda de la "liberalización", pues, el grado de seguridad del comercio de estos productos será mayor que el correspondiente a los industriales, ya que practicamente el 100 por ciento de los aranceles aplicables a los productos agrícolas quedarán "consolidados", en comparación con un 83 por ciento en el caso de los productos industriales.

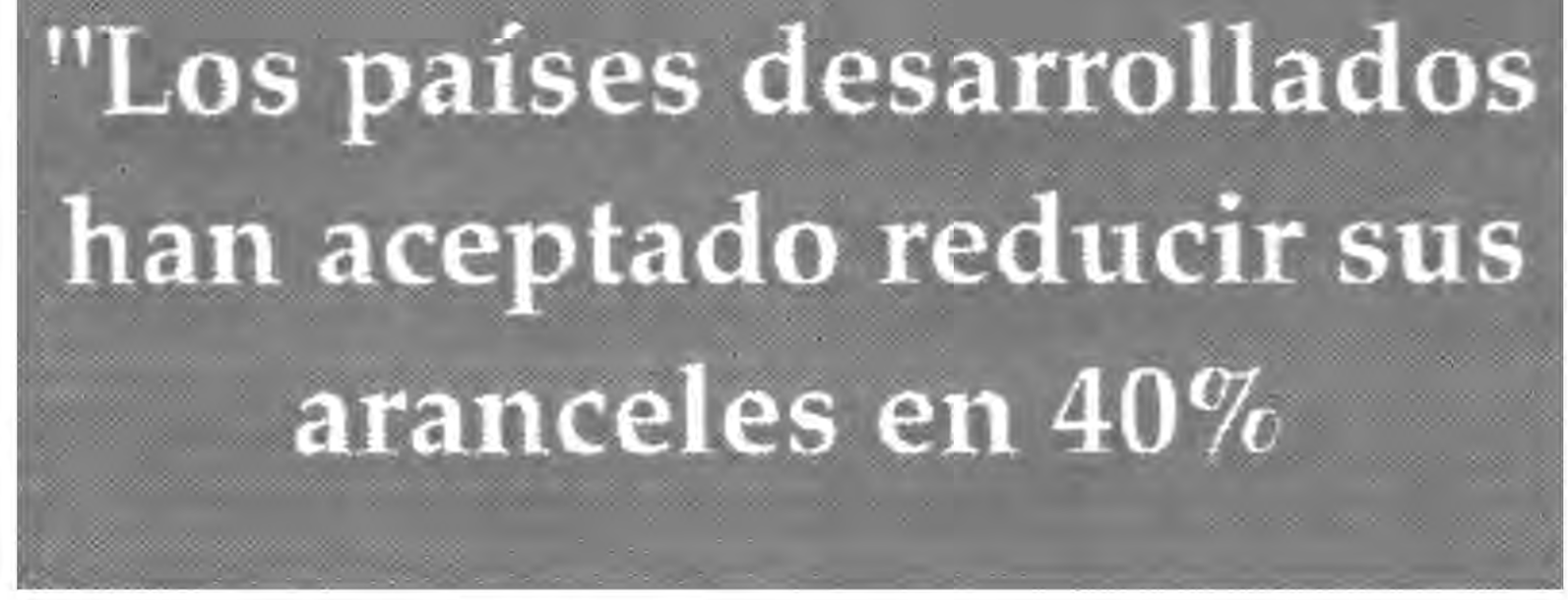

